\title{
Teaching Thoughts of Mathematics, Information and Control Courses
}

\author{
Xueyan Lin \\ Automation School \\ Beijing University of Posts and Telecommunications \\ Beijing, China \\ xylin@bupt.edu.cn
}

\author{
Qiqi Song \\ Automation School \\ Beijing University of Posts and Telecommunications \\ Beijing, China
}

\begin{abstract}
The purpose of this paper is to coordinate the relationship between the set up time, content and teaching methods of mathematics, and information and control courses in automatic control professions. We achieve goals by research visits, questionnaires, students' feedback and other methods. We should teach Complex Variable Function first, then Signal and System, and finally Automatic Control Principle. The three courses are offered in the third, the fourth and the fifth semester respectively, which are 2 credits, 2 credits and 4 credits required courses. To construct a reasonable knowledge on the content of teaching, the mathematics course focuses on the mathematical foundation and method, the information course focuses on the nature and application of the three transformations, strengthen their application in the field of automatic control. The control course focuses on the feedback, analysis and correction of the three performance indexes of the three major mathematical models in three analysis methods. In the teaching methods MATLAB will be applied to these three courses teaching, to stimulate students' learning interest and improve teaching effectiveness.
\end{abstract}

Keywords-Automatic Control Principle; Signals and Systems; Complex Variable Function; Curriculum integration and optimization; Teaching thoughts

\section{INTRODUCTION}

Automatic control principle is an important professional basic course of the mechanical engineering and automation, measurement and control technology and equipment, automation, logistics engineering and other professions in automation school, BUPT. Signal and system is the undergraduate professional basic course of communication engineering, information engineering, electronic engineering, automation and other professions in BUPT. Therefore, the automation school set automatic control principle, and signal and system as the main courses of the related professions. For the course of automatic control principle, the prerequisite lesson of mathematical class is complex variable function and the prerequisite lesson of information class is signal and system. The complex variable function has an important mathematical basis for mastering the control method of automatic control principle and signal and system analysis method [1].

In order to meet the needs of today's society for innovative talents, all colleges and universities are carrying out credit system reform. In the case that total credits remain unchanged or even reduced, reduce the theoretical teaching credits, increase practical teaching credits, and create innovative credits [2] The theoretical credits for the three courses offered by the automation school have been reduced to 8 credits, in which the complex variable function is 2 credits, the signal and system is 2 credits, and the automatic control principle is 4 credits. This paper puts forward some of teaching, thinking, discussion, suggestions and Solutions, from improving the effect of control system course in Automation College, and under the condition of the very limited number of hours.

\section{THE COURSES' CURRENT SITUATION AND PROBLEMS}

In the current training program of various professional in the automation school, such as measurement and control technology and instruments, the complex variable function is offered in the third semester, elective course and 2 credits. Signal and system course is offered in the fifth semester, the required course and 2 credits. The control engineering basic course is offered in the fifth semester, the required course, and theory 3 credits, experiment 1 credits. The signal and system and automatic control principle are offered in the fifth semester The same contents of the two courses, such as Laplace transform, Fourier transform, are repeated taught in the 2 classes, leading to duplication and waste of teaching resources, but also they are not recognized by students [3]

Although these three courses are co-opened, but independent teaching, only limited to the teaching of independent courses and doesn't take into account the links between it and other related courses. In BUPT, these three courses are assigned to the different schools. Teachers are appointed by the school of science, electronic engineering and automation to teach in accordance with the syllabus. The outline and textbook of the complex variable function is the basic course of the mathematics, the syllabus and teaching materials of the signal and system course is set for the communication majors and the course of the automatic control principle is set for the automation school. This does not meet the requirements of modern teaching and development trends. Part of the teaching content has been repeated, part of the content can't be connected, and the name is not uniform. Besides negative feedback, root trajectory analysis, Nyquist 
stability criterion, and control system correction, the course of automatic control principle has its own characteristics, the three kinds of transformation and system transfer functions are the same as the course of complex variable function and signals and systems [4]. Automatic control principle course is not repeated to explain the three transformations in detail, and will review and supplement the necessary properties of the three transformations.

The same basic concepts have different meanings in different courses. For example, the course of automatic control principle called "transfer function, pulse signal, initial conditions, frequency characteristics", in the Signals and Systems course called "system function, impulse signal, the starting state, spectrum." This will inevitably cause confusion on the understanding of students [5].

The common characteristics of these three courses are theoretical excess, a lot of formulas, transformations, concepts and theories. The courses are abstract and boring and mathematical deduction is tedious. Students generally feel they are difficult to understand, not to mention solid grasp and practical application [6]. The three courses have large numbers of failed students. For students, they love and hate these courses, at the same time they fell helpless. So the teaching effectiveness needs to be improved.

\section{TEACHING THOUGHTS AND SOLUTIONS}

\section{A. Teaching order proper arrangements}

The opening time and credit requirements of the courses included in the control class are recommended in table I, which can meet the theoretical teaching credit reduction requirements.

TABLE I COMPOSITION OF THE CONTROL CURRICULUM SYSTEM

\begin{tabular}{|c|c|c|c|}
\hline Course Name & Course Type & Open Time & $\begin{array}{c}\text { Course } \\
\text { Classification }\end{array}$ \\
\hline $\begin{array}{l}\text { Complex Variable } \\
\text { Function } \\
\text { And Integral } \\
\text { Transformation } \\
\end{array}$ & $\begin{array}{l}2 \text { credits, } \\
\text { compulsory }\end{array}$ & 3rd semester & $\begin{array}{l}\text { Mathematical } \\
\text { foundation }\end{array}$ \\
\hline Signal and System & $\begin{array}{c}2 \text { credits, } \\
\text { compulsory }\end{array}$ & 4th semester & $\begin{array}{c}\text { Subject } \\
\text { foundation }\end{array}$ \\
\hline $\begin{array}{l}\text { Automatic Control } \\
\text { Principle, Control } \\
\text { Engineering }\end{array}$ & $\begin{array}{l}4 \text { credits, } \\
\text { compulsory }\end{array}$ & 5th semester & $\begin{array}{c}\text { Professional } \\
\text { foundation }\end{array}$ \\
\hline $\begin{array}{c}\text { Modern Control } \\
\text { Theory, Computer } \\
\text { Control }\end{array}$ & $\begin{array}{l}2 \text { credits, } \\
\text { compulsory }\end{array}$ & 6th semester & $\begin{array}{l}\text { Professional } \\
\text { knowledge }\end{array}$ \\
\hline
\end{tabular}

The opening of complex variable function and Signal and System course prior to the automatic control principle is reasonable. What has already appeared in the previous course will appear again in the next course, it is only necessary to review and supplement without having to go through the details. This will avoid the repetition of the previous three classes, save time and also improve teaching efficiency.

\section{B. Constructing reasonable teaching knowledge system}

Complex variable function course mainly teaches the basic theory and method, including complex and complex function, analytic function, and integral of complex variable function, series, Fourier transform and Laplace transform [7]. Signal and system mainly introduces the basic concepts, principles and methods of signal and system. The contents include the basic concepts, time domain analysis, frequency domain analysis and $\mathrm{S}$ domain analysis for continuous signal and system, time domain analysis, frequency domain analysis and $\mathrm{Z}$ domain analysis of discrete signals and systems, the state space analysis of the system and random signals are analyzed by linear system and so on [8]. Automatic control principle or control engineering foundation mainly introduces the basic content of classical control theory, including the basic concepts of automatic control, three mathematical models (differential equations, transfer function, frequency characteristics), three analysis methods (time domain analysis, frequency domain analysis, root trajectory analysis), three evaluation indicators (stability, accuracy and rapidity), system correction, nonlinear control systems and sampling control systems [9].

These three courses can't be replaced each other, and have different emphases. Complex variable function is the basic course of mathematics [10]. Signal and system mainly focus on the signal processing of the system, such as convolution of signals in frequency domain. The system may be the filter, coding system, communication system and modulation system and so on. The automatic control system is mainly the feedback control system and the emphasis is placed on system stability and control accuracy, noise immunity, and speed. The repeated content parts are quite good for students to deepen the understanding of the content. The teachers of three courses communicate with each other and promote each other.

In the course of the teaching of complex function, the teacher should strengthen the content that plays an important role in the course of automatic control principle, its practical application, and the basic concepts of complex numbers, Fourier transform and Laplace transformations, but weaken the mathematical theory, the contents of the complex integral, and the series, the residues and analytical functions etc. [11]

In the course of the teaching of the signal and system, the teacher should emphasize the mathematical concepts, physical concepts and engineering concepts of Fourier transform, Laplace transform and $\mathrm{Z}$ transform. The mean teaching contents include time domain analysis, frequency domain analysis and complex frequency domain analysis of continuous signals and systems, and time domain analysis and $\mathrm{Z}$ domain analysis of discrete signal and system. There is no need to master the concrete solution process of various complex solutions in differential equations and difference equations, and just understand its basic concepts and physical meaning.

In the course of automatic control principles, the basic concepts part of signal and system should not be taught again and mainly introduce the basic theory of signals and systems course to analyze and solve problems in engineering practice. The course should focus on the analysis and control of linear control system, and significantly cut away from the actual application scenarios and theoretical too strong part, such as the exit angle and the incident angle of the root locus, the equivalent transformation law of the structure diagram, the frequency characteristic analysis of the closed loop system, a line of all zero in the Routh criterion, and the proof of the Nyquist criterion with integral part. 


\section{Focus on the combination of three courses}

The two courses for complex functions and signals and systems offered by automation students, must satisfy the Automation Institute's characteristic and to student's training request. The teachers should fully understand the role of these two courses on the automatic control related courses and practice and apply them in practical teaching.

Complex variable function course is very theoretical and the content is very abstract. In the complex function part there are many definitions, theorem and other conceptual knowledge to understand, the content is boring. In the integral transformation part of the content is mostly transform and derivation formula, there are many calculation method need to be mastered [12]. This requires students to have a good foundation for higher mathematics. Coupled with the majority of students do not know how to link with the actual, resulting in their learning is very difficult, only know the formula to solve the math problem. Learning passive but gain little effect [13]. In fact, the course for understanding and master the principle of automatic control of the three major analytical methods have an important role in the analysis and control system and have a very important significance for the three performance indicators. As in the root trajectory analysis of the control system, it is necessary to calculate the root point of the root locus, which involves the problem of polynomial equation rooting and complex roots. When the intersection of the root trajectory and the imaginary axis is made, the concept of the real part and the imaginary part is equal to zero when the complex number is equal to zero. And the symmetry of the root trajectory is obtained according to the nature of the conjugate complex number. It is recommended that when explaining the basic concepts the teachers should link it to the application of the follow-up course.

In the automation school, the signal and system course only has 2 credits, so the course content must have a choice. It is focus on analyzing the continuous signal with the system, appropriately translating the discrete signal with part of the system. It should emphasize the three transformations of mathematical concepts, physical concepts and engineering concepts, including continuous signal and system time domain analysis, frequency domain analysis and complex frequency domain analysis, discrete signal and system $\mathrm{Z}$ domain analysis. Signal and system is set up before automatic control principle course, so the purpose of teaching is to enable students to master the nature of the three transformations and applications. If students learn automatic control principle course on this basis, they can strengthen the link between theory and practice, so as to further develop their engineering concept.

The Automatic control principle course focuses on the application of Laplace transform and Fourier transform in time domain analysis and frequency domain analysis. It requires students to establish the concept of feedback control system, master the feedback control system mathematical model, such as transfer function, structure and equivalent transformation, Mason formula, frequency characteristics, master the stability of the automatic control system, accuracy, fast performance evaluation of these three aspects of the evaluation and analysis as well as the integrated control and design of the control system [14].

As for the problem of two courses have different names but same content, it is necessary that the teachers consult and unite in advance. In the course of teaching they should explain it to the students, so as to avoid confusion and confusion. Automatic control principle in the automatic major is called for control engineering foundation in other majors. In fact the contents of these two courses are identical. They both belong to the classic control theory category but use different names. To accommodate the construction of the course platform, it is recommended that the names be unified into Automatic Control Principle.

\section{Using MATLAB when teaching}

The three courses, complex variable function, signal and system, and automatic control principle, have common characteristic, that is, the theory is too strong. There are a lot of formulas, transformations, concepts, and the traditional classroom teaching is abstract, boring and cumbersome, resulting in students do not learn initiative. And MATLAB has a powerful computing power and rich graphics capabilities, can demonstrate the generation of the curve, so that classroom teaching becomes vivid and intuitive [15]. In automatic control principle course, after introduced the theoretical knowledge of the eight rules of the root trajectory, we can use the command rlocus ( ) in MATLAB to draw the root locus of the control system. Not only through the color of the curve to distinguish the root locus branch, can we see the curve of the direction. MATLAB has a powerful dynamic system simulation toolbox Simulink, in the course can be a very good application, in order to improve the course of fun and teaching quality [16]. In Signals and Systems course can also use the MATLAB to design convolution calculation, filter design and spectral characteristics curve.

\section{SUMMARY AND PROSPECT}

Automation school in BUPT is very concerned about automatic control principle, and now has passed the school reform and experimental tutorial project, which provides the necessary support for the implementation of the teaching reform of automatic control principle course. Re-adjust the order of the three courses of complex variable function, signal and system and automatic control principle, integrating the repetitive teaching content, paying attention to the organic combination of three courses, to build a reasonable teaching knowledge system. And using MATLAB when teaching, trying to combine theory and practical application, to mobilize the enthusiasm of students in order to obtain a higher quality of teaching and teaching efficiency.

\section{REFERENCES}

[1] Nai-Gang Hong, Yu-Yan Chen, Ming Xu. Research on Integral Transformation of Complex Variable Function and Integration of Related Courses [J]. Journal of East China Metallurgical Institute (Social Science Edition), 2000, 2 (3): 75-76.

[2] Ping Li, Guo-Zhong Liu. Integration and optimization of "Circuit Principle", "Signal and System" and "Automatic Control Principle" course [J]. Optical Technology, 2007, 11 (33): 243-245. 
[3] Bo Xu, Xiao-Ping Chen, Wei Ji. Thinking and practice of teaching reform of "Signal and System" course [J] .Journal of Electrical \& Electronic Education. 2008, 30 (1): 8-10.

[4] Rong Chen, Kai-Ru Zhang. "Automatic Control Principle" on the electronic information engineering profession [J]. Electrical and Electronic Teaching, 2002, 24 (4): 29-31.

[5] Zheng-Qiang Zhang. Scientific inquiry "Automatic Control Principle" and "Signal and System" [J]. Electrical and Electronic Teaching, 2008, 30 (3): 12-13.

[6] Zhu Zhu. "Signal and System" and "Automatic Control Principle" course co-opened teaching thinking [J]. Times education, 2009, 3: 50-51.

[7] Mian-Sen Wang. Complex Function (Fourth Edition) [M]. Beijing: Higher Education Press, 2011.

[8] Jun-Li Zheng, Qi-Heng Ying, Wei-Li Yang. Signal and System (Third Edition) [M]. Beijing: Higher Education Press, 2011.

[9] Shou-Song Hu. Automatic Control Principle (Sixth Edition) [M]. Beijing: Science Press, 2013.

[10] [Ping Lu, Zhuan-Zhuan Liu, Ming Yang. Complex Function and Integral Transformation Teaching Content Reform [J]. Journal of North University of China (Social Science Edition), 2007, 12(23): 168-169.
[11] Wen-Juan Jiang. The integration of "Complex Function and Integral Transformation" and "Automatic Control Principle" [J]. Education and Teaching Forum, 2013 (41): 212-213.

[12] Xue-Hua Zhao, Na Zhang. Curriculum characteristics and countermeasures of complex function and integral transformation [J]. Science and Technology Information, 2010 (27):132-143.

[13] Juan-Juan Gao, Shu-He Wang. "Complex Function and Integral Transformation" course teaching reform [J]. China Electric Power Education, 2014 (17):63-64.

[14] Zhao-Ling Chen, Guo-Hai Liu, Nian-Fa Yang. "Automatic Control Principle" course all-round teaching reform and practice $[\mathrm{J}]$. China Electric Power Education .2013 (5): 86-87.

[15] Yuan-Lu Li. "Signal and System" course teaching reform thinking and practice [J]. China Electric Power Education .2002, 2 (131): 42-43.

[16] Run-Sheng Li, Ying Yang. Teaching Reform and Practice of Automatic Control Principle Course [J]. Journal of Liaoning Institute of Science and Technology.2010, 12 (3): 63-64. 